\title{
Research on Integrated Marketing Communication in the Mobile Internet Environment
}

\author{
Yu Cao \\ Wuhan Donghu University, Wuhan, Hubei, China, 430212 \\ hunter2011@foxmail.com
}

Keywords: Integrated marketing communication, Mobile internet environment, Mobile internet age.

\begin{abstract}
The mobile internet has rapidly developed into one of the most eye-catching phenomenon of the global field of information and communication in recent years. This paper gives the concept of mobile internet and integrated marketing communication, and then provides three suggestions to the development of the integrated marketing communication in the mobile internet era, including simplify channel entrance, standardize business processes and unify information management in order to supply references for the related researchers.
\end{abstract}

\section{Concept and Features of Mobile Internet}

Mobile internet is the integration of internet technology and mobile communication technology through a variety of portable smart devices to achieve access to the network information and services anytime and anywhere. Mobile internet has realized the mobile function of wireless communication, the traditional computing function and the direct integration function of internet.

Mobile internet is a product of the integration of mobile communication and traditional internet. It not only retains the advantages of traditional internet information, space and search convenient, but also can make full use of the characteristics of mobile communication, convenient, personalized and ubiquitous. Mobile terminal volume, easy to carry, the user can almost not be limited to any time and place, use the phone to send and receive information. As long as there is cell phone signal coverage, mobile internet users can carry out information dissemination and reception anytime and anywhere. Users use the mobile internet is mainly focused on the way to work, travel, waiting, leisure and entertainment, such as fragmentation of the time, the use of more than a few minutes, which is typical of people's life time. Mobile microblog, mobile video, mobile phone QQ and other business are designed to meet the needs of people who only have the fragmented time. Information production and distribution of traditional media need a longer fixed period. Under the mobile internet environment, anyone can become a publisher, receiver and forwarding of information, and the acceptance and release of information is no longer limited by time and space. Interaction is an important feature of the mobile internet. It allows users to choose need to choose the information according to their own preferences, so that the individual can truly achieve freedom, equality and democracy to communicate and feedback to each other.

\section{Concept and Development of Integrated Marketing Communication}

Since the concept of integrated marketing communication has been officially put forward in the end of 1980s, the research on integrated marketing communication has been defined and studied from different perspectives. With the continuous development of the practice, integrated marketing communication concept are also more and more abundant. The earliest definition of integrated marketing communication is given by the American Advertising Association. It will integrate marketing communication as a marketing communication plan. It is considered that the marketing communication plan is to evaluate various methods. Tang Schultz believes that integrated marketing communication is to manage all the information related to the product or service to manage the process, so that consumers or potential consumers access to the integration of information, resulting in purchasing behavior, and maintain brand loyalty. He believes that the cores of integrated marketing communication is the integration of internal resources, and fully mobilize 
all positive factors that can be utilized in order to achieve the goal of corporate communications. Integrated marketing communication emphasizes the contact with customers, and through these contact points to the consumers of corporate image. In modern society, the information quantity presents the geometric growth way, people's living environment is also constantly changing, leading to the change of idea. Traditional integrated marketing communication theory emphasizes the product as the center, the integration of all marketing tools. Mobile Internet era must be done online and offline integration and achieve seamless docking connection.

\section{Strategies of Integrated Marketing Communication in the Mobile Internet Environment}

Simplify Channel Entrance. Simplifying the channelentrance to get through online and offline channels is an important step to achieve integrated marketing communication in the mobile internet environment. Customers want to achieve the most convenience in the shopping phase. For example, in the store to see the real family of products, but cannot immediately decide whether to buy, then of course, there is hope that there is a means to provide online product search and display. Then the enterprise can use the two-dimensional code scanning technology, the two-dimensional code printed on the label, the customer online store after the enterprise mobile client application scanning two-dimensional code, you can see the corresponding product in the online business mobile client, home and family to discuss. If the customers are satisfied, the product can be purchased and paid online, and then select the logistics distribution or offline store.

Simplify the channel entrance can greatly enhance the conversion rate of the channel entrance technology. In addition to the two-dimensional code, the technology also covers face recognition to locate VIP customer information, RFID to get active tag data. These are all through the digital, automated information transfer mode, simplifying the registrations, login, search, query and other complex operations. They also break the customer's cross channel shopping process, improve the customer experience, and achieve the consistency of cross channel access. Second, we look at the stage of supporting services. For customer service the most satisfied, the most will give priority to the interactive channel is still the phone, think the phone's efficiency is the highest. Through the investigation we found that most of the customers at the beginning of the customer communication is starting from the network, but in the end, most people will choose in turn links artificial seat, and customers most satisfied with the channel business also telephone service. From this we can find that when customers have problems or transactions become particularly complex, they will choose one of the most simple, the fastest way to solve the problem, so from the perspective of customers, hope that the enterprise cross channel integrated marketing process to provide a unified, fast and fast service entrance. For companies to deploy customer communication way customers want through the enterprise for the cross channel information more integration, customer service center of artificial seat can obtain more other channels of information. Companies also need to use technology, for customers across different channels to retain transaction scenarios', including customer identity and behavior. The customers do not need to cross the channel service means to provide the same information.

StandardizeBusiness Processes. Cross channel customers want to have a unified enterprise in addition to a unified page, search, product display, and so on. After simplifying the channel entrance into the shopping process, the most important thing is to unify the online and offline business processes to achieve cross channel business line on the line. Unified cross channel customer experience is a revolutionary process. Operations management needs to be planned from a strategic point of view. Improving the customer experience is not the solution to improve the management of the contact points, but the customer's shopping process is embedded into the operation mode and operation process of the enterprise. We are generally less likely to put the process engine in the mobile application of mid, hope can activate and server-side business process execution. Although the integration is time-consuming and laborious, but this is the front desk can be involved in the business opportunities, but also in the business driven, there is a chance to transform the background of the old business process. Tomorrow's market winners should be able to provide a cross channel experience design, allowing customers to cross a wide variety of channels 
and access points to search, buy, and seamless access to services. Moreover, not only to provide personalized products and services, but also to ensure timeliness. A company is able to provide a successful experience, which depends on their coordination and allows more than one enterprise, from the contents of the supply chain partners to the supply chain partners to the business process to maintain the same. Today's customers are seeking a consistent experience across multiple channels from the search. Standardizing business processes of on-line and off-line to provide smooth, efficient and flexible serviceis now the key to customer satisfaction.

In order to achieve cross channel strategy, a large number of business processes, such as quotation, promotion, order management, service management, inventory management need to be unified. Order processing orders for process integration settings backend centralized processing center, to ensure that each channel set radiolabeling acceptance ability, improve processing efficiency. At the same time, the establishment of a visual monitoring platform for the internal business external customers to achieve real-time visibility of order processing process, enhance customer participation, and then get a better customer experience. Logistics and distribution process based on efficient logistics and distribution capabilities to ensure that cross channel sales delivery capabilities, enhance customer experience is the most important aspect of cross channel business collaboration. "The last mile" of the logistics and distribution service is the enterprise's pain, is a challenge and opportunity. Payment process integration channel payment and back-end business model management process convergence and consistency of payment data is an important part of the customer experience. In recent years, the rise of the third party payment services, including Wechat pay and Alipay, also greatly drives the development of the on line and off line business collaboration.

Unify Information Management. Enterprise integrated marketing communication should realize the centralized management of product information. Generally speaking, for the well-known brand, it has a relatively fixed customer groups, and the channels of the product is also aimed at the consumer habits of these customers set. When the company set up a new channel, will face with the original channels of different customers, the purchase habits and preferences will not be the same. If the sale is exactly the same product, it will not meet the needs of this difference, but also may cause dilution of the original channels, resulting in customer churn. Therefore, it is needed to form a unified product information management, which not only ensures the information management of the cross channel overlap products, but also ensures the difference of product information management. In addition, in addition to the product category of management, the price is also related to the channel, and customers for different channels for price sensitivity are also different. For example, online channels for customers for the most sensitive, and therefore the price of discount promotions and other management tools must provide. And like the store, especially the high-end store customers for the service and the environment are far greater than the sensitivity of the price itself. So we need to develop products for different channels.Customer information management in the process of cross-channel integration of the enterprise will be through different customer contact points to collect different angles of customer information. Mobile internet has brought the explosive growth of customer data, enterprises need to analyze and share the mass data from different channels. Will these customer information collection and collation, the formation of a unified information view, to provide customers with information support to provide information support to customers across the channel. These come with different channels of customer information, such as basic customer data, customer service and support information, purchase preferences and shopping behavior information, as well as the relevant information collected on the Internet, but also for the portrait of customers, customer segmentation, to achieve cross marketing and precision marketing, to provide more detailed and thoughtful service. The perfect member management enables the customer to choose from any channel as the contact point to the purchase process, can quickly identify and locate the customer information, especially the member customer information. Based on the analysis of the basic data and behavior information of the customers provided by the unified information management, we can make the precise marketing to enhance the efficiency of integrated marketing communication. 


\section{Conclusion}

We are in the blooming era of mobile internet. Compared with the traditional integrated marketing communications, the integrated marketing communications in the mobile internet era have some new and different elements. We should simplify the channel entrance to keep cross channel accessconsistency, implement online and offline business collaborative to keepcross channel business cooperation and complete the enterprise ecological informationsharing to keep sharing of data across the channel to optimize the integrated marketing communications in the mobile internet environment.

\section{References}

[1] Y.A. Wang, The Applied Research of Electronic Integrated MarketingCommunication on Festival and Special Event, Dongbei University of Finance and Economics, 2013.

[2] X. Li, A Research on the New Media Integrated Marketing Communications of Tourism Destination, Nankai University, 2014.

[3] L. Tian, Enterprise Cross-channel Integration Marketing Research in Mobile Internet Era, Beijing Jiaotong University, 2015.

[4] Y. Zhang, Integrated Marketing Communication Strategy under the Background of New Media Technology, Journal of China Youth University for Political Sciences, 4(2011)115-117.

[5] K.P. Zhao, New Media Marketing Strategy in the Age of Internet-Coca-Cola New Nickname Bottle as an Example, Journal of Jincheng Institute of Technology, 4(2015)83-85. 